\title{
Association of the Serotonin 2A Receptor rs6311 Polymorphism with Diurnal Preference in Koreans
}

\author{
Ji Won Yeom', Seunghwa Jeong ${ }^{1,2}$, Ju Yeon Seo ${ }^{1,2}$, Sehyun Jeon ${ }^{1,2}$, and Heon-Jeong Lee ${ }^{1,2} \bowtie$ \\ ${ }^{1}$ Department of Psychiatry, Korea University College of Medicine, Seoul, Republic of Korea \\ ${ }^{2}$ Chronobiology Institute, Korea University, Seoul, Republic of Korea
}

Objective Evidence for the association between circadian rhythm delay and depression is accumulating. Genetic studies have shown that certain polymorphisms in circadian genes are potential genetic markers of diurnal preference. Along with circadian genes, there is a growing interest in other genetic effects on circadian rhythms. This study evaluated whether the HTR2A rs6311 (-1438C/T) polymorphism is associated with diurnal preference in a Korean population.

Methods A total of 510 healthy subjects were included in this study. All subjects were genotyped for the HTR2A rs6311 polymorphism and they completed the Korean version of the composite scale of morningness (CSM).

Results The $\mathrm{C}$ allele carriers $(\mathrm{C} / \mathrm{C}+\mathrm{C} / \mathrm{T})$ showed significantly higher $\mathrm{CSM}$ scores compared to $\mathrm{C}$ allele non-carriers $(\mathrm{T} / \mathrm{T})(\mathrm{t}=2.22, \mathrm{p}=$ 0.03), suggesting the existence of a morning chronotype tendency in $\mathrm{C}$ allele carriers. In other words, the T/T genotype may be associated with the evening chronotype.

Conclusion These results suggest that the HTR2A rs6311 polymorphism may be associated with diurnal preference in a healthy Korean population. The absence of the $\mathrm{C}$ allele may be responsible for the increasing susceptibility to eveningness in the Korean population. Further studies on HTR2A polymorphisms that evaluate their interactions with various candidate genes and differences in phenotypic expression of polymorphisms according to ethnic groups are warranted to fully understand their association with diurnal preference.

Psychiatry Investig 2020;17(11):1137-1142

Key Words Diurnal preference, HTR2A, Polymorphism, Morningness.

\section{INTRODUCTION}

Evidence for the association between circadian misalignment and mood disorders is accumulating. ${ }^{1-3}$ It is empirically well known that an irregular sleep-wake cycle in bipolar disorder leads to depression or mania, and sleep-wake cycle abnormalities precede mood changes. ${ }^{1}$ A recently published study on circadian misalignment of mood episodes that involved hospitalized bipolar patients revealed that acute manic episodes were associated with circadian dysregulation with $\mathrm{a}-17 \mathrm{~h}$ phase delay, mixed manias were delayed for $>6 \mathrm{~h}$, and bipolar depression was associated with $4-5 \mathrm{~h}$ phase delays compared

Received: September 19, 2020 Revised: October 21, 2020

Accepted: October 23, 2020

$\triangle$ Correspondence: Heon-Jeong Lee, MD, PhD

Department of Psychiatry, Korea University Anam Hospital, Korea University College of Medicine, 73 Goryeodae-ro Seongbuk-gu, Seoul 02841, Republic of Korea

Tel: +82-2-920-6721, Fax: +82-2-6280-5810, E-mail: leehjeong@korea.ac.kr

(c) This is an Open Access article distributed under the terms of the Creative Commons Attribution Non-Commercial License (https://creativecommons.org/licenses/by$\mathrm{nc} / 4.0$ ) which permits unrestricted non-commercial use, distribution, and reproduction in any medium, provided the original work is properly cited. to the controls in the study. ${ }^{2}$ Circadian rhythmicity, thus, is an important genetic factor that contributes to the bipolar disorder pathogenesis and recurrence. ${ }^{4}$ Previous studies indicated that circadian genes also influence bipolar disorder trait markers, such as circadian phase preference for the evening. ${ }^{4,5}$

Diurnal preference, also referred to as chronotype, is an individual's phenotypic trait, which reflects the time of day with the highest activity and performance level. Chronotypes are evaluated using questionnaires, including the composite scale of morning (CSM). The three chronotypes of circadian typology introduced by Adan et al. ${ }^{6}$ include the following: morning-type, evening-type, and neither-type. Individuals with the morning-type chronotype have a relatively advanced sleepwake cycle and perform best early in the day while those with the evening-type chronotype have a relatively delayed sleepwake cycle and perform best later in the day. Forty percent of the adult population are either morning-type or evening-type, and sociodemographic factors, such as age and sex, are known to influence chronotype across the life span. ${ }^{6}$ Diurnal preference is widely studied for its association with psychiatric dis- 
orders, specifically mood disorders, eating disorders, and addictions. ${ }^{6}$ The evening-type has been found to have a significant positive association with a number of psychiatric symptoms, such as sleep disturbance and depression, even after controlling for confounding factors including age, sex, education, civil status, physical activity, alcohol consumption, smoking status, and body mass index.-9

This diurnal variation in mental and physical performance is considered to be closely associated with, if not generated by, endogenous circadian rhythms. ${ }^{10}$ Circadian rhythms are driven by intracellular molecular mechanisms, which in turn are controlled by the transcriptional-translational feedback of the clock genes located in the suprachiasmatic nucleus of the anterior hypothalamus. ${ }^{11,12}$ This transcriptional-translational feedback loop contributes to the generation of a roughly 24 -h rhythmic expression pattern of clock genes. ${ }^{12}$ The dimerization of the transcription factors circadian locomotor output cycles kaput (CLOCK) and brain and muscle Arnt-like (ARNTL) or neuronal pas domain protein 2 (NPAS2) proteins initiates the expression of clock proteins period (PER) and cryptochrome (CRY). ${ }^{13}$ Subsequently, the heterodimerized PER and CRY proteins translocate to the nucleus and inhibit CLOCK-ARNTL or CLOCK-NPAS2 activity, resulting in the negative feedback of their own expression. ${ }^{10}$ According to previous studies, polymorphisms of the clock genes are associated with diurnal preference: CLOCK 3111C/T single nucleotide polymorphism (SNP) rs 1801260, ${ }^{14,15} A R N T L$, and ARNTL2 in mood disorder patients $^{16,17}$ and polymorphisms in PER homologs (PER1, PER2, and PER3) in the general population., ${ }^{8,10,14,18-20}$

In addition to the core circadian clock genes, other genes have been investigated for their association with diurnal preference. One candidate for such an investigation could be the 5HT2A receptor (HTR2A). The HTR2A gene, located on chromosome 13q14-q21, ${ }^{21}$ is composed of three exons and two introns). ${ }^{22}$ Human HTR2A binding is altered in patients with suicidal and aggressive behaviors, major depression, and schizophrenia. ${ }^{23}$ Specifically, the association between HTR2A promoter region polymorphism (HTR2A $-1438 \mathrm{C} / \mathrm{T})$ and seasonal affective disorder has been investigated; previous studies have reported inconsistent findings. ${ }^{24,25}$ According to Lee et al., ${ }^{26} \mathrm{HTR} 2 \mathrm{~A}$ $-1438 \mathrm{~A} / \mathrm{G}$ SNP was found to be associated with seasonality in Korean college students. The HTR2A gene contains a polymorphism $(102 \mathrm{C} / \mathrm{T})$, and this polymorphism is in absolute linkage disequilibrium with a polymorphism $(-1438 \mathrm{C} / \mathrm{T})$ in the promoter region of the gene..$^{27}$ The $102 \mathrm{C} / \mathrm{T}$ polymorphism of the HTR2A gene was also found to be associated with the seasonal pattern in major depression. ${ }^{27}$ The relationship between the $-1438 \mathrm{C} / \mathrm{T}$ polymorphism of the HTR2A gene and seasonality, with circadian misalignment as one hypothesis of its pathophysiology, ${ }^{28}$ makes this polymorphism a reasonable candidate for investigating the association with diurnal preference.

In this study, we examined the association between diurnal preference and a polymorphism, HTR2A rs6311 (-1438C/T) SNP, in healthy Korean adults. We also assessed the effects of genotype and allele carrier status on the mean total and three subscale (morningness, morning alertness, and activity planning) scores of CSM. We hypothesized that the HTR2A 1438T allele is associated with lower mean total and subscale scores of CSM.

\section{METHODS}

\section{Subjects}

A total of 510 healthy Korean adults aged 18-35 years were recruited through an online advertisement. An experienced psychiatrist confirmed that none of the participants had lifetime or current psychiatric disorders based on the results of the Mini-International Neuropsychiatric Interview. Study participants also did not have any major medical problems; those with a family history of substance abuse or major psychiatric disorders (e.g., schizophrenia or major mood disorders) were excluded. All 510 subjects (male/female ratio=303/207; mean age, 23.41 years; range, 18-35 years) completed the Korean version of the Composite Scale of Morningness (CSM). All participants provided informed consent prior to enrollment in the study. The study protocols were approved by the Ethics Committee of Korea University (IEC No. 1067), and the study was conducted according to the Declaration of Helsinki. Other findings involving these study subjects have been previously reported. ${ }^{10,29-32}$

\section{Assessment of diurnal preference}

Diurnal preference was evaluated using the CSM, which was developed by Smith et al. ${ }^{33}$ in 1989. The CSM consists of 13 items, which are further classified into three subscales: morningness (items 1, 3, 6, 8, 10, and 11), activity planning (items 2 , $7,9,13$ ), and morning alertness (items 4,5 , and 12) (9). Of the 13 items, three items were scored on a five-point scale (ranging from 1 to 5) and the remaining 10 items were scored on a four-point scale (ranging from 1 to 4 ). The total CSM score ranges from 13 to 55; a higher score indicates a morning preference and vice versa. The CSM is not only psychometrically as accurate as the Horne and Ostberg's morningness-eveningness questionnaire but also shorter in length. ${ }^{33,34}$ All participants were asked to complete the Korean version of CSM. ${ }^{35}$ The validity of the Korean version of CSM was established by Yoon et al. ${ }^{35}$

\section{Genotyping}

Genomic DNA was extracted from leukocytes using the 
QIAamp DNA Blood Mini Kit (QIAGEN, Hilden, Germany). Genotyping was performed using high-resolution melting curve analysis. ${ }^{36}$ Polymerase chain reaction (PCR) was performed in a $20-\mu \mathrm{L}$ reaction mixture and a 96-well CFX96 Real-Time PCR System (BioRad Laboratories, Hercules, CA, USA). The reaction mixture consisted of $2 \mu \mathrm{L}$ genomic DNA (template), $200 \mathrm{mM}$ of primer HTR2A[rs6311], forward primer (5'-TTA GGC TGA AGG GTG AAG A-3'), reverse primer (5'-CAC TCT GGA CAC AAA CAC T-3'), SsoFast EvaGreen Supermix ( $1 \times$ final concentration; BioRad Laboratories, Inc.), and sterile $\mathrm{H}_{2} \mathrm{O}$. The amplification protocol starts with an initial denaturation step at $98^{\circ} \mathrm{C}$ for $3 \mathrm{~min}$, followed by 39 cycles of denaturation at $98^{\circ} \mathrm{C}$ for $10 \mathrm{~s}$ and $58^{\circ} \mathrm{C}$ for $20 \mathrm{~s}$. After an initial step at $95^{\circ} \mathrm{C}$ for $10 \mathrm{~s}$ and $65^{\circ} \mathrm{C}$ for $10 \mathrm{~s}$, melting curves were generated from $65^{\circ} \mathrm{C}$ to $95^{\circ} \mathrm{C}$, in increments of $0.2^{\circ} \mathrm{C}$ at each cycle. Melting profiles were analyzed using Precision Melt Analysis software (BioRad Laboratories, Hercules, CA, USA).

\section{Statistical analysis}

The presence of Hardy-Weinberg equilibrium was tested using the chi-square $\left(\chi^{2}\right)$ test for goodness of fit. Analysis of covariance (ANCOVA) with sex as a covariate was performed to examine the effects of genotypes on the mean total CSM score and mean scores of the three CSM subscales (morningness, activity planning, and morning alertness). The Student's t-test was used to determine the effects of allele carrier status on the mean total CSM and its subscale scores. A two-tailed, alpha $=0.05$ test was chosen for the analysis. All statistical analyses were performed using SPSS version 22.0 for Windows (IBM, Corp., Armonk, NY, USA).

\section{RESULTS}

Of the 510 subjects included in this study, 303 (59.4\%) were male and $207(40.6 \%)$ were female, with an age range of 18 to 35 years (mean \pm SD, $23.1 \pm 2.8$ years). The total CSM scores ranged from 14 to 51 , with a mean score of $32.1 \pm 6.4$. Table 1 shows the mean total CSM scores and mean scores of the three subscales that were classified based on the HTR2A -1438C/T polymorphisms. The genotypic distributions of the HTR2A $-1438 \mathrm{C} / \mathrm{T}$ polymorphisms followed Hardy-Weinberg equilibrium and were not significantly different $\left(\chi^{2}=2.7, p=0.1\right)$. In addition to genotype comparison, the study subjects were compared according to their allele carrier status. No significant differences were observed in the mean total CSM scores and mean scores of the three subscales among the genotypes of the HTR2A rs6311 (-1438C/T) polymorphism $(\mathrm{F}=2.48, \mathrm{p}=0.08$ for total CSM; $F=2.26, p=0.10$ for morningness; $F=2.03, p=0.13$ for morning alertness; and $\mathrm{F}=1.80, \mathrm{p}=0.17$ for activity planning). Although there were no statistically significant results, a general propensity was noted in the results. The T/T genotype in this study was found to be associated with lower mean total and subscale scores of CSM than $\mathrm{C} / \mathrm{C}$ and $\mathrm{C} / \mathrm{T}$ genotypes. There was no significant difference in the mean scores of the two subscales based on the $\mathrm{C}$ allele carrier status $(\mathrm{t}=1.52$, $\mathrm{p}=$ 0.13 for morning alertness and $\mathrm{t}=1.91, \mathrm{p}=0.06$ for activity planning). However, $\mathrm{C}$ allele non-carriers had significantly lower mean scores for total CSM $(\mathrm{t}=2.22, \mathrm{p}=0.03)$ and the morningness subscale $(t=2.10, p=0.04)$ than $\mathrm{C}$ allele carriers. The mean total CSM score for the three genotypes $(\mathrm{F}=2.48, \mathrm{p}=0.08)$ and the mean score for the activity planning subscale for the $\mathrm{C}$ allele carriers and $\mathrm{C}$ allele non-carriers $(\mathrm{t}=1.91, \mathrm{p}=0.06)$ were marginally significant.

Table 1. Composite scale for morningness scores in subject groups according to the HTR2A rs6311 (-1438C/T) polymorphism

\begin{tabular}{|c|c|c|c|c|}
\hline & \multicolumn{4}{|c|}{ CSM score } \\
\hline & Morningness & Morning alertness & Activity planning & Total \\
\hline \multicolumn{5}{|l|}{ Genotypes } \\
\hline $\mathrm{C} / \mathrm{C}(\mathrm{N}=149)$ & $15.75 \pm 3.42$ & $7.37 \pm 1.82$ & $9.17 \pm 2.27$ & $32.30 \pm 6.51$ \\
\hline $\mathrm{C} / \mathrm{T}(\mathrm{N}=236)$ & $15.67 \pm 3.44$ & $7.62 \pm 1.69$ & $9.32 \pm 2.20$ & $32.61 \pm 6.40$ \\
\hline $\mathrm{T} / \mathrm{T}(\mathrm{N}=125)$ & $14.97 \pm 3.31$ & $7.25 \pm 1.76$ & $8.83 \pm 2.07$ & $31.05 \pm 6.06$ \\
\hline $\mathrm{F}$ & 2.26 & 2.03 & 1.80 & 2.48 \\
\hline $\mathrm{p}$-value & 0.10 & 0.13 & 0.17 & 0.08 \\
\hline \multicolumn{5}{|l|}{ Allele carriers } \\
\hline C carriers $(\mathrm{N}=385)$ & $15.70 \pm 3.43$ & $7.52 \pm 1.74$ & $9.26 \pm 2.22$ & $32.50 \pm 6.44$ \\
\hline C non-carriers $(\mathrm{N}=125)$ & $14.97 \pm 3.31$ & $7.25 \pm 1.76$ & $8.83 \pm 2.07$ & $31.05 \pm 6.06$ \\
\hline $\mathrm{t}$ & 2.10 & 1.52 & 1.91 & 2.22 \\
\hline $\mathrm{p}$-value & $0.04^{*}$ & 0.13 & 0.06 & $0.03^{*}$ \\
\hline
\end{tabular}

${ }^{*} \mathrm{p}<0.05$. CSM: composite scale for morningness 


\section{DISCUSSION}

This study investigated the association between HTR2A $-1438 \mathrm{C} / \mathrm{T}$ polymorphisms and diurnal preference. We found that $\mathrm{C}$ allele non-carriers ( $\mathrm{T} / \mathrm{T}$ genotype) had significantly lower mean scores for the total CSM and morningness subscale than $\mathrm{C}$ allele carriers $(\mathrm{C} / \mathrm{C}+\mathrm{C} / \mathrm{T}$ genotypes). Although the mean total and three CSM subscale scores were not significantly associated with $H T R 2 A-1438 \mathrm{C} / \mathrm{T}$ genotypes, the T/T genotype had lower scores than the $\mathrm{C} / \mathrm{C}$ and $\mathrm{C} / \mathrm{T}$ genotypes. In addition, the mean total CSM score of the three genotypes and the mean score of activity planning subscale for $\mathrm{C}$ allele carriers and $\mathrm{C}$ allele non-carriers showed marginal significance.

To the best of our knowledge, this is the first study to investigate the association between HTR2A polymorphisms, including the $-1438 \mathrm{C} / \mathrm{T}$ polymorphism, and diurnal preference. Previous studies on HTR2A polymorphisms have focused mainly on the relationship between gene polymorphisms and various psychiatric disorders, including mood and eating disorders, impulsivity and suicidal behavior, and addiction. Seasonality, with seasonal affective disorder at the extreme on the continuum, was found to be associated with the HTR2A -1438A allele, ${ }^{24}$ which is consistent with the result of a study conducted in healthy Korean young adults. ${ }^{26}$ Since eveningness is known to be associated with seasonal affective disorder, ${ }^{37-39}$ the finding of the present study that $\mathrm{T} / \mathrm{T}$ genotype and $\mathrm{C}$ allele non-carriers showed lower CSM scores with a propensity towards eveningness, is consistent with those of previous studies. This association between eveningness and seasonality could be explained by the possible common underlying mechanism of circadian rhythm, which in turn leads to the clinical implication that chronotherapeutics, primarily light therapy, could also have meaningful effects as an intervention modality for pathologies related to eveningess. ${ }^{40}$ Furthermore, it could be postulated that $-1438 \mathrm{C} / \mathrm{T}$ polymorphism is associated with neuropsychiatric disorder through circadian disruption.

Nonetheless, in one study conducted to investigate the association between HTR2A 102C/T polymorphism and depression with seasonal patterns, it was found that the seasonal pattern was 7.57 times more frequent in $102 \mathrm{C}$ allele carriers than in $102 \mathrm{~T}$ homozygous carriers. ${ }^{27}$ Furthermore, the $\mathrm{C}$ allele of the HTR2A 102C/T polymorphism was shown to be associated with neuropsychiatric diseases, even though this finding is controversial. ${ }^{41}$ The $102 \mathrm{C} / \mathrm{T}$ polymorphism of the HTR2A gene does not result in changes in the amino acid sequence of the receptor protein. However, it is in absolute linkage disequilibrium with a polymorphism $(-1438 \mathrm{~A} / \mathrm{G})$ in the promoter region of the gene. Therefore, the $-1438 \mathrm{~A}$ allele is most likely accompanied by the $102 \mathrm{~T}$ allele while the $-1438 \mathrm{G}$ allele is most likely accompanied by the $102 \mathrm{C}$ allele. This inconsistency with the results of the present study could be explained by the possible ethnic differences in the expression of HTR2A gene polymorphisms ${ }^{42}$ and the underestimated effect of the polymorphisms on diurnal preference due to the underlying complex mechanism with a number of internal and external factors. Thus, further studies on how the phenotypic expression of HTR2A polymorphisms may be different in ethnic groups and how it affects the association between HTR2A gene polymorphisms and diurnal preference are needed.

The current study has several limitations. First, population stratification bias cannot be excluded. However, the Korean population is known to have a relatively high degree of genetic homogeneity $;^{43}$ thus, it would be reasonable to assume that population stratification bias in our study participants is unlikely. In addition, the study sample represents a very homogenous population because it comprised healthy young adults with the same ethnicity. Second, the sample size may not be large enough to fully assess the effect of the HTR2A -1438C/T polymorphism on diurnal preference. Although our sample size $(n=510)$ was not smaller than those of previous gene studies on diurnal preference, it may not have caught all the effects of the polymorphism, if it worked only as one component of a complex network. Third, the possible effects of occupations on diurnal preference need to be considered. It would have been more informative if specific occupations, such as those that involve shiftwork, were taken into consideration in the analysis. However, most of the participants were college students.

In conclusion, HTR2A -1438C/T polymorphism may be associated with diurnal preference in the Korean population. The propensity of the $\mathrm{T} / \mathrm{T}$ genotype and $\mathrm{C}$ allele non-carriers to have lower mean total and CSM subscale scores was noted; the absence of the $\mathrm{C}$ allele may be responsible for the increase in the susceptibility of healthy Koreans to eveningness. Due to the limited research on HTR2A gene polymorphisms and diurnal preference, future studies to investigate various candidate genes in different ethnic groups are needed to improve our understanding of genetic influence on the phenotypic expression of circadian rhythmicity in the form of diurnal preference. Further research would be also clinically meaningful because pharmacological interventions acting on serotonin receptors may help regulate diurnal preference, especially eveningness, which is widely associated with numerous psychiatric disorders.

\section{Acknowledgments}

This study was supported by the Korea Health 21 R\&D Project funded by the National Research Foundation of Korea (2017M3A9F1031220 and 2019R1A2C2084158).

\section{Conflicts of Interest}

The authors have no potential conflicts of interest to disclose. 


\section{Author Contributions}

Conceptualization: Heon-Jeong Lee. Data curation: Ju Yeon Seo, Sehyun Jeon. Formal analysis: Ji Won Yeom, Heon-Jeong Lee. Funding acquisition: Heon-Jeong Lee. Investigation: Ji Won Yeom, Seunghwa Jeong. Methodology: Ji Won Yeom, Seunghwa Jeong, Sehyun Jeon. Project administration: Ju Yeon Seo, Heon-Jeong Lee. Resources: Heon-Jeong Lee. Software: Ji Won Yeom, Seunghwa Jeong, Sehyun Jeon. Supervision: Heon-Jeong Lee. Validation: Heon-Jeong Lee. Visualization: Ji Won Yeom. Writing-original draft: Ji Won Yeom. Writing—review \& editing: Heon-Jeong Lee.

\section{ORCID iDs}

$\begin{array}{ll}\text { Ji Won Yeom } & \text { https://orcid.org/0000-0003-0038-2101 } \\ \text { Seunghwa Jeong } & \text { https://orcid.org/0000-0003-3850-9243 } \\ \text { Ju Yeon Seo } & \text { https://orcid.org/0000-0003-1312-761X } \\ \text { Sehyun Jeon } & \text { https://orcid.org/0000-0002-6594-6556 } \\ \text { Heon-Jeong Lee } & \text { https://orcid.org/0000-0002-9560-2383 }\end{array}$

\section{REFERENCES}

1. Lee HJ. Circadian misalignment and bipolar disorder. Chronobiol Med 2019;1:132-136.

2. Moon JH, Cho CH, Son GH, Geum D, Chung S, Kim H, et al. Advanced Circadian Phase in Mania and Delayed Circadian Phase in Mixed Mania and Depression Returned to Normal after Treatment of Bipolar Disorder. EBioMedicine [Internet] 2016;11:285-295. Available at: http://dx.doi.org/10.1016/j.ebiom.2016.08.019.

3. Lamont EW, Legault-Coutu D, Cermakian N, Boivin DB. The role of circadian clock genes in mental disorders. Dialogues Clin Neurosci 2007;9:333-342.

4. Geoffroy PA. Clock genes and light signaling alterations in bipolar disorder: when the biological clock is off. Biol Psychiatry [Internet] 2018; 84:775-777. Available at: https://doi.org/10.1016/j.biopsych.2018.09.006.

5. Bellivier F, Geoffroy PA, Etain B, Scott J. Sleep- and circadian rhythmassociated pathways as therapeutic targets in bipolar disorder. Expert Opin Ther Targets 2015;19:747-763.

6. Adan A, Archer SN, Hidalgo MP, Di Milia L, Natale V, Randler C. Circadian typology: a comprehensive review. Chronobiol Int 2012;29: 1153-1175.

7. Ellis J, Von Schantz M, Jones KHS, Archer SN. Association between specific diurnal preference questionnaire items and PER3 VNTR genotype. Chronobiol Int 2009;26:464-473.

8. Lee HJ, Kim L, Kang SG, Yoon HK, Choi JE, Park YM, et al. PER2 variation is associated with diurnal preference in a Korean young population. Behav Genet 2011;41:273-277.

9. Randler C, Díaz-Morales JF. Morningness in German and Spanish students: a comparative study. Eur J Pers 2007;21:419-427.

10. Song HM, Cho CH, Lee HJ, Moon JH, Kang SG, Yoon HK, et al. Association of CLOCK, ARNTL, PER2, and GNB3 polymorphisms with diurnal preference in a Korean population. Chronobiol Int [Internet] 2016;33:1455-1463. Available at: http://dx.doi.org/10.1080/07420528.2 016.1231199 .

11. Liu AC, Welsh DK, Ko CH, Tran HG, Zhang EE, Priest AA, et al. Intercellular coupling confers robustness against mutations in the SCN circadian clock network. Cell 2007;129:605-616.

12. Takahashi JS, Hong HK, Ko CH, McDearmon EL. The genetics of mammalian circadian order and disorder: Implications for physiology and disease. Nat Rev Genet 2008;9:764-775.

13. Garbazza C, Benedetti F. Genetic factors affecting seasonality, mood, and the circadian clock. Front Endocrinol (Lausanne) 2018;9:1-9.

14. Katzenberg D, Young T, Finn L, Lin L, King DP, Takahashi JS, et al. A CLOCK polymorphism associated with human diurnal preference. Sleep 1998;21:569-576.

15. Mishima K, Tozawa T, Satoh K, Saitoh H, Mishima Y. The 3111T/C polymorphism of hClock is associated with evening preference and delayed sleep timing in a Japanese population sample. Am J Med Genet - Neuropsychiatr Genet 2005;133B:101-104.

16. Lavebratt C, Sj?holm LK, Partonen T, Schalling M, Forsell Y. PER2 variantion is associated with depression vulnerability. Am J Med Genet Part B Neuropsychiatr Genet 2010;153B:570-581.

17. Shi J, Wittke-Thompson JK, Badner JA, Hattori E, Potash JB, Willour VL, et al. Clock genes may influence bipolar disorder susceptibility and dysfunctional circadian rhythm. Am J Med Genet Part B Neuropsychiatr Genet 2008;147B:1047-1055.

18. Archer SN, Carpen JD, Gibson M, Lim GH, Johnston JD, Skene DJ, et al. Polymorphism in the PER3 promoter associates with diurnal preference and delayed sleep phase disorder. Sleep 2010;33:695-701.

19. Carpen JD, Von Schantz M, Smits M, Skene DJ, Archer SN. A silent polymorphism in the PER1 gene associates with extreme diurnal preference in humans. J Hum Genet 2006;51:1122-1125.

20. Lee HJ, Paik JW, Kang SG, Lim SW, Kim L. Allelic variants interaction of CLOCK gene and G-protein $\beta 3$ subunit gene with diurnal preference. Chronobiol Int 2007;24:589-597.

21. Sparkes RS, Lan N, Klisak I, Mohandas T, Diep A, Kojis T, et al. Assignment of a serotonin 5HT-2 receptor gene (HTR2) to human chromosome 13q14-q21 and mouse chromosome 14. Genomics 1991;9: 461-465.

22. Chen K, Yang W, Grimsby J, Shih JC. The human 5-HT2 receptor is encoded by a multiple intron-exon gene. Mol Brain Res 1992;14:20-26.

23. Khait VD, Huang YY, Zalsman G, Oquendo MA, Brent DA, HarkavyFriedman JM, et al. Association of Serotonin 5-HT2A receptor binding and the T102C polymorphism in depressed and healthy caucasian subjects. Neuropsychopharmacology 2005;30:166-172.

24. Enoch MA, Goldman D, Barnett R, Sher L, Mazzanti CM, Rosenthal NE. Association between seasonal affective disorder and the 5-HT(2A) promoter polymorphism, -1438G/A. Mol Psychiatry 1999;4:89-92.

25. Johansson C, Smedh C, Partonen T, Pekkarinen P, Paunio T, Ekholm J, et al. Seasonal affective disorder and serotonin-related polymorphisms. Neurobiol Dis 2001;8:351-357.

26. Lee HJ, Sung SM, Lim SW, Paik JW, Leen Kim. Seasonality associated with the serotonin $2 \mathrm{~A}$ receptor $-1438 \mathrm{~A} / \mathrm{G}$ polymorphism. J Affect Disord 2006;95:145-148.

27. Arias B, Gutiérrez B, Pintor L, Gastó C, Fãanás L. Variability in the 5-HT2A receptor gene is associated with seasonal pattern in major depression. Mol Psychiatry 2001;6:239-242.

28. Lewy AJ, Sack RL, Singer CM, White DM. The phase shift hypothesis for bright light's therapeutic mechanism of action: theoretical considerations and experimental evidence. Psychopharmacol Bull 1987;23: 349-353.

29. Ju H, Cho CH, Moon JH, Kim L, Lee HJ. Association of the RORA gene polymorphism and diurnal preference in a young Korean population. Sleep Med Psychophysiol 2016;23:25-28.

30. Nam YJ, Cho CH, Kim L, Lee HJ. Association of G-protein $\beta 3$ subunit C825T polymorphism with seasonal variations in mood and behavior. Psychiatry Investig 2018;15:200-204.

31. Kim HI, So SJ, Yang HJ, Song HM, Moon JH, Yoon HK, et al. Association of the RORA gene polymorphism and seasonal variations in mood and behavior. Sleep Med Psychophysiol 2013;20:63-68.

32. Kim HI, Lee HJ, Cho CH, Kang SG, Yoon HK, Park YM, et al. Association of CLOCK, ARNTL, and NPAS2 gene polymorphisms and seasonal variations in mood and behavior. Chronobiol Int 2015;32:785791.

33. Smith CS, Reilly C, Midkiff K. Evaluation of three circadian rhythm questionnaires with suggestions for an improved measure of morningness. J Appl Psychol 1989;74:728-738.

34. Greenwood KM. Long-term stability and psychometric properties of the compositescale of morningness. Ergonomics 1994;37:377-383.

35. Yoon JS, Shin SM, Kook SH, Lee HY. A preliminary study on the Korean translation of composite scale (KtCS) to measure morningness: eveningness. J Korean Neuropsychiatr Assoc 1997;36:122-134. 
36. Vossen RHAM, Aten E, Roos A, Den Dunnen JT. High-resolution melting analysis (HRMA) - More than just sequence variant screening. Hum Mutat 2009;30:860-866.

37. Tonetti L, Fabbri M, Martoni M, Natale V. Circadian type and mood seasonality in adolescents. Psychiatry Clin Neurosci 2012;66:157-159.

38. Natale V, Adan A, Scapellato P. Are seasonality of mood and eveningness closely associated? Psychiatry Res 2005;136:51-60.

39. Lee HJ, Rex KM, Nievergelt CM, Kelsoe JR, Kripke DF. Delayed sleep phase syndrome is related to seasonal affective disorder. J Affect Disord 2011;133:573-579.

40. Geoffroy PA. The light of hope in antidepressant strategies. Chronobi- ol Med 2020;2:57-60.

41. Jobim PFC, Prado-Lima PAS, Schwanke CHA, Giugliani R, Cruz IBM. The polymorphism of the serotonin-2A receptor T102C is associated with age. Brazilian J Med Biol Res 2008;41:1018-1023.

42. Lam LCW, Tang NLS, Ma SL, Zhang W, Chiu HFK. 5-HT2A T102C receptor polymorphism and neuropsychiatric symptoms in Alzheimer's disease. Int J Geriatr Psychiatry 2004;19:523-526.

43. Han GR, Lee YW, Lee HL, Kim SM, Ku TW, Kang IH, et al. A Korean population study of the nine STR loci FGA, VWA, D3S1358, D18551, D21S11, D8S1179, D7S820, D13S317 and D5S818. Int J Legal Med 2000;114:41-44 